\title{
Composition of Barrow Island Collembolan fauna: analysis of genera
}

\author{
Penelope Greenslade ${ }^{1,2,3}$ \\ ${ }^{1}$ Environmental Management, School of Science, Information Technology and Engineering, \\ University of Ballarat, Mt Helen, Ballarat, Victoria 3353, Australia. \\ Email: Pgreenslade@staff.ballarat.edu.au \\ 2 School of Biology, Australian National University, Australian Capital Territory 0200, Australia. \\ ${ }^{3}$ South Australian Museum, North Terrace, Adelaide, South Australia 5000, Australia.
}

\begin{abstract}
Collembola have been collected from Barrow Island for the first time; a maximum of seventy one species were detected, of which a high proportion are undescribed. Only four nonindigenous species (NIS) species have been collected, three in very small numbers but one was a large population introduced to the island in lengths of timber which were subsequently sent off the island. Despite few of the species being described, most have been collected before and endemism is low. One new genus record for Australia, Calx, was found. The presence of a species of Temeritas is unusual in that the males showed strong sexual dimorphism, and a species of Acanthocyrtus that lacked any pigment was collected in reasonable numbers. Collections from bore holes were rich in species. Five species were recorded only from bore holes and may be island endemics. The intertidal fauna was also rich in species with 14 found, all restricted to this habitat. Soil fauna density of Collembola was found to be high, with a mean average potential density of nearly $47,000 / \mathrm{m}^{2}$. A proportion of the terrestrial Collembola fauna is active under all weather conditions but other species are only active after rain. In general, the terrestrial fauna shows a dominance of the families Isotomidae and Bourletiellidae, which is typical for the wet/dry tropics where trees are absent.
\end{abstract}

KEYWORDS: generic richness, species richness, endemism, troglobites, new records, sexual dimorphism

\section{INTRODUCTION}

Barrow Island is currently the best sampled of Australia's islands for Collembola with the exception of subantarctic Macquarie Island. However, the latter has a much smaller fauna (Greenslade 2006) and is under different constraints of climate and isolation. Barrow Island can be considered a severe climate for invertebrates, being in the wet/dry tropics and dry for most of the year. As described by Callan et al. (2011) and elsewhere by Majer et al. (2013), the island has been comprehensively sampled over four years during the baseline survey, which took place under a variety of different weather conditions. Currently, monitoring, using a regime of sampling for the purposes of surveillance for exotic species, is being undertaken, which is more limited both in terms of habitats, methods and area sampled (Whittle et al. 2013; Majer et al. 2013). The baseline survey was designed to document the whole invertebrate fauna and to detect non indigenous species (NIS), while the surveillance protocol was custom-designed to detect target species of concern (Whittle et al. 2013).
In fact, only a small proportion of the total known collembolan fauna is being collected during the surveillance sampling. Despite the limitations of the surveillance sampling, this surveillance has, over two years, collected one native collembolan species not recorded before.

There was considerable value in documenting the Barrow Island (BI) Collembola before construction of the liquid natural gas plant and associated facilities, because the island is a rare example of a minimally disturbed, fairly large, continental island with a fauna that is representative of the mainland fauna before European and, indeed, Indigenous, human habitation (DEC 2011). Moreover, although mainly minute and inconspicuous, the Collembola represent a high proportion of total invertebrate individuals on the island and are an important component of the decomposer guild of organisms (Larsen 2007 and included references). Collembola are the third most speciose Class of arthropods after Insecta and Arachnida known from the island. Compared to all hexapod Orders, Collembola are the seventh most speciose group. 
The description of the island and its history to date are given in a previous chapter (Moro and Lagdon 2013), so will not be repeated here. Suffice to say that the vegetation and topography are fairly uniform over all the island, and so habitats are limited for Collembola compared to islands with higher topography, and with fresh water aquatic and forested areas. The most varied habitat is on the coast, where a variety of plant associations in the fringing vegetation, substrates, slopes, aspects and wave intensity are present.

\section{METHODS}

In the pilot study and baseline sampling (Gas Plant Study), the full range of sampling methods was used to collect Collembola. These were leaf litter extraction, vacuuming and beating vegetation, pitfall traps, light traps and hand searching. The surveillance phase comprises all of these methods except for beating and light trapping but adds yellow window traps (see Majer et al. 2013 for full description of methods, and Callan et al. 2011). A specific field trip was made by the author for five days in June 2010 to collect Collembola from habitats and using methods not employed in either the pilot and baseline study or in the surveillance. A focus was directed to marine littoral habitats using small pitfall traps, soil core extraction and to sampling leaf litter and soil from sites where introductions within the camp sites such as plant beds might occur. Methods and sites used in this field trip are described in detail in Greenslade (2010). A collection of Collembola from sink holes has also been made and the fauna identified.

As part of a project to barcode Australian collembolan species, 20 species from Barrow Island have been bar-coded (see Table 1). The sequences will be used in wider analysis of Australian and other species in each individual genus.

\section{RESULTS}

\section{COMPOSITION AND SIZE OF THE FAUNA}

The total number of species distinguished to date is a maximum of 71 including four unconfirmed species, represented by 45 genera including two unconfirmed genera in 15 families (Table 1). Three Australian families were not found, namely Dicyrtomidae, Spinothecidae and Tomoceridae. Species in these families have no ability to survive periodically and predominately dry conditions. Only three species in three genera (Hypogastrura vernalis (Carl), Isotoma sp. cf. viridis Nicolet and ?Mesaphorura sp.) were found which may represent non-indigenous species (NIS) but these were only sampled in low numbers. They may have been specimens from elsewhere that had accidentally fallen into samples or they may have extremely low and restricted populations on the island (Table 1). One potential NIS in the genus Entomobrya was detected during quarantine (pre-border) inspection of timber which initially did not seem to have dispersed to the island and had not been collected before on the island but was common in disturbed habitats in southern Australia. The timber was returned to the mainland.

\section{COMPARATIVE FAUNAS}

The Entomobryidae is the most generically diverse family found on the island, followed by Isotomidae. The Bourletiellidae is the third most species rich family. This family richness is normal for periodically arid climatic regions throughout Australia where native grasses are present. The Neanuridae are more species rich on Barrow Island than is normally found in other parts of the arid zone and wet dry tropics because of the presence of several neanurid species in marine littoral habitats (Figure 1).

Five other well-sampled sites in Australia, covering a latitudinal range from $12^{\circ}$ to $45^{\circ}$, are Lamington National Park (LNP) (Greenslade and Kitching 2011), Lord Howe Island (LHI) (Greenslade 2003), Macquarie Island (MI) (Greenslade 2006), Sweers Island (Greenslade 2005) and Koonamore (Greenslade unpublished data). By 'well-sampled' is meant that field collections were made on a number of occasions at different seasons of the year and under different weather conditions. Most other localities in Australia have only been collected once and so their species lists are less complete. The total number of species at 71 for Barrow Island, 69 for LNP and 67 for LHI are similar in order of magnitude but subantarctic MI has less than half that number of species.. The same is true for the number of genera, being 45 for BI, 47 for LNP and 42 for LHI, while again Macquarie Island has half that number of genera. Sweers Island, a small island in the Gulf of Carpentaria under a similar climate to Barrow Island, has a small fauna of 16 genera and 17 species (Greenslade 2005). It has been highly impacted by grazing and development in the past. However, the intensely collected arid locality, Koonamore in South Australia, has recorded 30 genera and 47 species. This is high for an arid site and is because parts of the property has been undisturbed for over 50 years, grazing is low and collections have been made under all weather conditions on seven field trips (Figure 1).

When family signatures are compared in more detail over this latitudinal range of over $30^{\circ}$ for all 
TABLE $1 \quad$ List of genera from Barrow Island.

* Denotes a non indigenous species, square brackets denote a tentative identification based on a single damaged individual.

\# Denotes species in the genus have been barcoded.

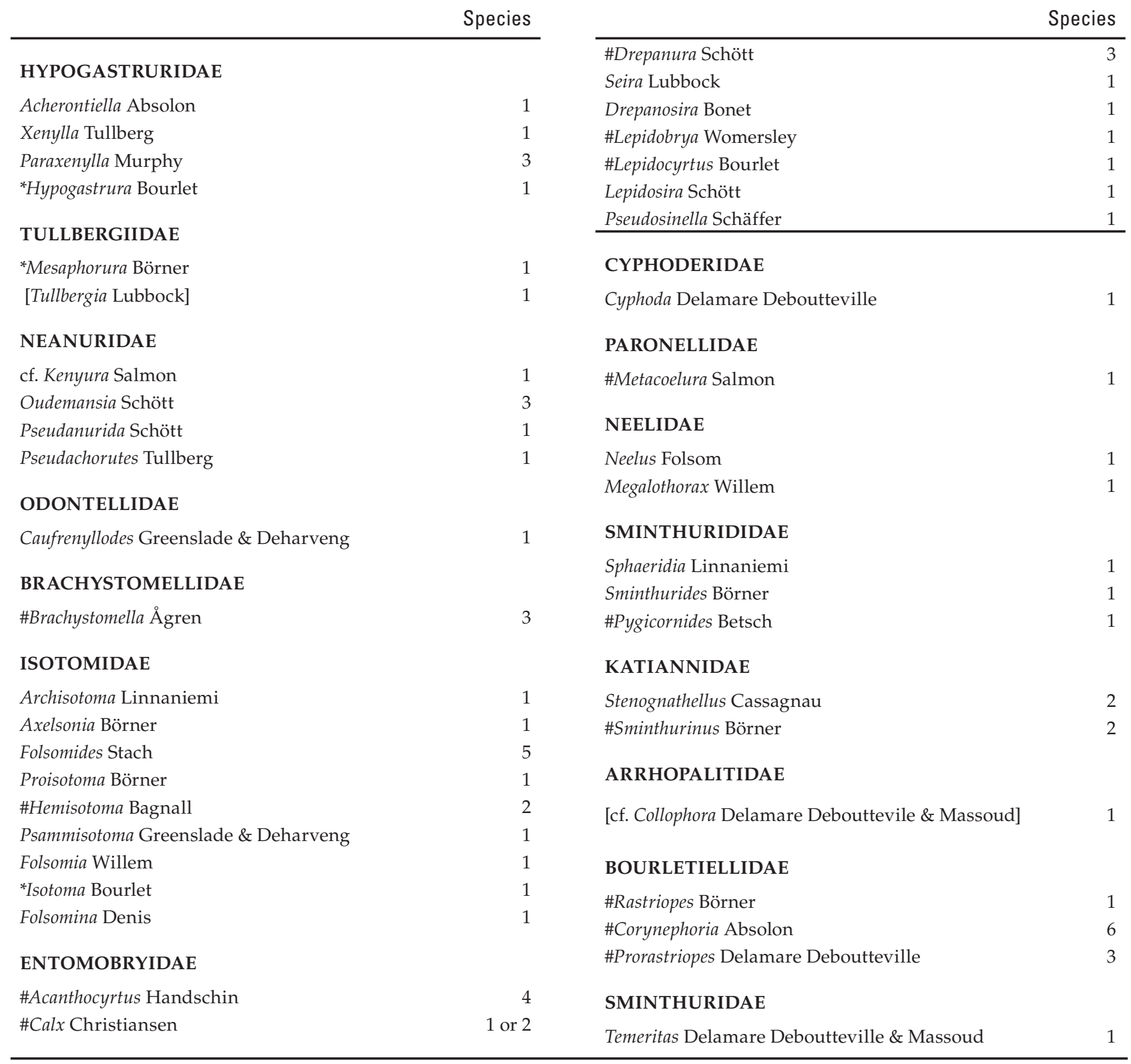

six sites (Figure 1), the Isotomidae are most speciesrich but become more dominant moving south, while the Entomobryidae become less species- and generic-rich at the same time. In the same way, the Bourletiellidae become less diverse moving out of the arid zone until they are absent altogether from Macquarie Island, while the representation of Katiannidae increases except on the arid site. These differences not only reflect a latitudinal gradient and/or climatic differences such as moisture regimes, but also the different habitats, in particular the vegetation present at each location. Although species in both Bourletiellidae and Katiannidae occur on grasses, habitats of most Entomobryidae and Isotomidae are more variable. Species of Entomobryidae live mainly in leaf litter and on vegetation, while species of Isotomidae live not only in leaf litter but also in humus and soil. These differences in abiotic and biotic conditions are also reflected in the different family representation at the different sites (Figure 1). 


\section{HABITATS}

\section{EPIGAEIC FAUNA}

The epigaeic fauna, that is the species on vegetation that are collected by vacuuming or sweeping with a net, seem to be active under all weather conditions. They only comprise species of
Symphypleona, Entomobryidae and Paronellidae. The main genera represented are Corynephoria, Rastriopes, Drepanura and Metacoelura (Figures 2d, e, f). Species of Corynephoria and Metacoelura are almost exclusively only associated with native grasses and both genera are endemic to Australia, with one species each in Indonesia. Corynephoria is particularly species-rich in arid and semi-arid
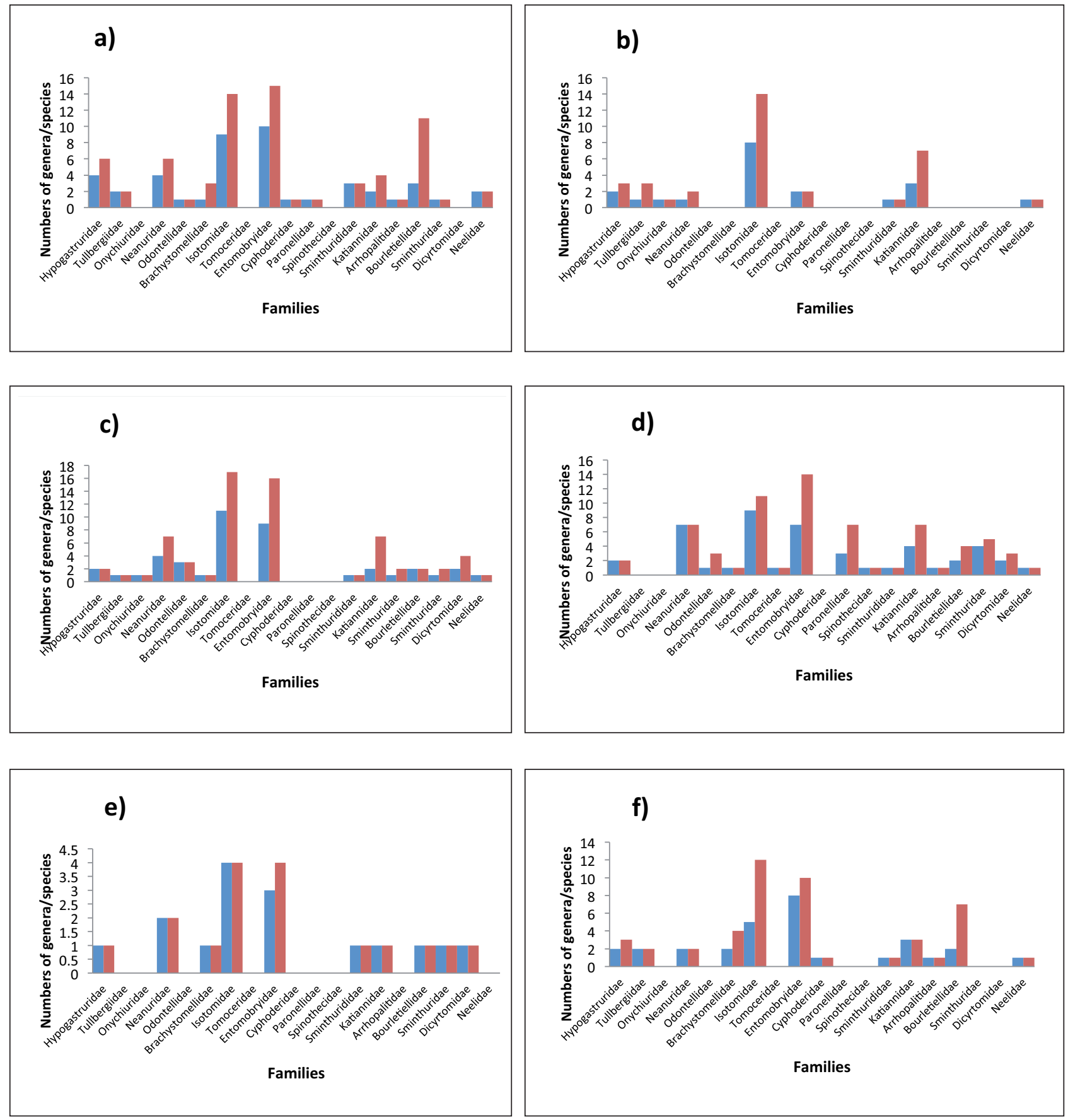

FIGURE 1

Histogram of family signatures of genera and species of six localities in Australia, a) Barrow Island, b) Macquarie Island, c) Lord Howe Island, d) Lamington National Park, e) Sweers Island and f) Koonamore. Generic richness shown by blue columns, species richness shown by red columns. 
parts of Australia and is the most species rich genus on Barrow Island, with six species. It has been shown statistically to be exclusively found on native grasses (Greenslade et al. 2012). Metacoelura is also only found on native grasses but is confined geographically to the northern third of the Australian continent.

\section{SOIL FAUNA}

A total of just over 3,000 individual Collembola were collected from the 35 soil cores taken from seven sites in June 2010 (Greenslade 2010). The mean average density of Collembola in soil was 47,000 per $\mathrm{m}^{2}$. There were few other invertebrates collected in the cores. As the cores were moistened before the fauna was extracted, the density represents the potential fauna that would be active after a rainfall event. This figure is considerably higher than densities obtained for arid regions on the mainland, that are more than an order of magnitude lower at around 2,000 and 3,000 animals per $\mathrm{m}^{2}$ (Greenslade 2009). Ninety-four per cent of the animals collected from Barrow Island soil cores were either immature Symphypleona or adult Folsomides spp., both groups hatching or activated by moistening. When the immature Symphypleona are omitted, the density is lower at 17,000 per $\mathrm{m}^{2}$. The immature Symphypleona were patchy in distribution and were probably restricted to sites under shrubs where leaf litter was present. Most Symphypleona specimens belonged to the genus Sphaeridia but other genera, such as Stenognathellus, were present. Folsomides spp. were also patchy in distribution.

\section{INTERTIDAL FAUNA}

Fourteen species belonging to eleven genera were found in the intertidal zone. Each beach type contained a different suite of species and up to seven species were found on some beaches. The intertidal Collembola found belonged to the genera Acherontiella, Kenyura, Paraxenylla, Oudemansia, Brachystomella (1 species of 3 in total of this genus on the island), Seira, Lepidosira, Psammisotoma, Archisotoma, Axelsonia, Pseudanurida and Caufrenyllodes, the latter being collected supralittorally. All species in these genera, but only six of the genera, are restricted to the intertidal or supralittoral zone. The genera Kenyura and Caufrenyllodes are rare and have not been found in the intertidal zone before. Such a high overall and $\beta$ diversity of the intertidal fauna has not been found in Australia within such a small area. Schlacher et al. (2007) note that the distinctive diversity of sandy beaches is not widely recognised, nor is their functional importance. Human activities and perturbation will result in adverse ecological ramifications requiring policies to be developed to limit or prevent these disturbances (Schlacher et al. 2007). As no other collections have been made from marine littoral habitats in north-western Western Australia, it is not possible to ascertain if any of the marine littoral species are locally endemic or more widespread in similar habitats in Australia. However local endemism is unlikely, as marine littoral species normally have wide distributions because they are able to disperse over long distances on debris floating in oceans.

\section{BORE HOLES}

A collection of over 200 specimens were collected from bore holes, mainly located north west of the residential accommodation. Details of the bore hole collections are given in Humphreys et al. (2013). The specimens belonged to seven species in four families. Only two of the genera had been found on Barrow Island previously. All species but one, Folsomina onychiurina Denis, almost certainly belonging to undescribed species. Most specimens belonged to the genus Pseudosinella. This genus is abundant in moist underground cavities throughout Australia. The second most abundant species belonged to the genus Megalothorax, a minute, moist, soil living genus. Cyphoda also found, is a rare inquiline genus and specimens are only found in association with ants or termites.

Although the number of samples per region and per bore hole varied, there is an indication that the mean number of specimens per bore with the bores grouped according to their code number shows that the sites most distant from the Texaco camp at 7 or more $\mathrm{km}$ had the most specimens per sample (8.17 and 6.5 to 7 respectively) while the bores at from 1.3 to $5.8 \mathrm{~km}$ from the camp have fewest at ( 3.3 to 4.4 respectively). However a single bore sample from $7.1 \mathrm{~km}$ had only 2 individuals. Altogether, this collection added at least six new species records to the island's fauna.

\section{RARE SPECIES, NEW RECORDS OF GENERA}

One new generic record, Calx, for Australia was identified from the Barrow Island collections (Figure 2b). Two different colour forms were found which may reflect two different species or sexual or other dimorphism within a single species (Figure $2 b)$ but only a few individuals were collected and then only from a single collection. There are only four species described in the genus, these being from North America, Chile, Central America and the Virgin Islands, all from very different habitats. The record of two species from Barrow Island is a 

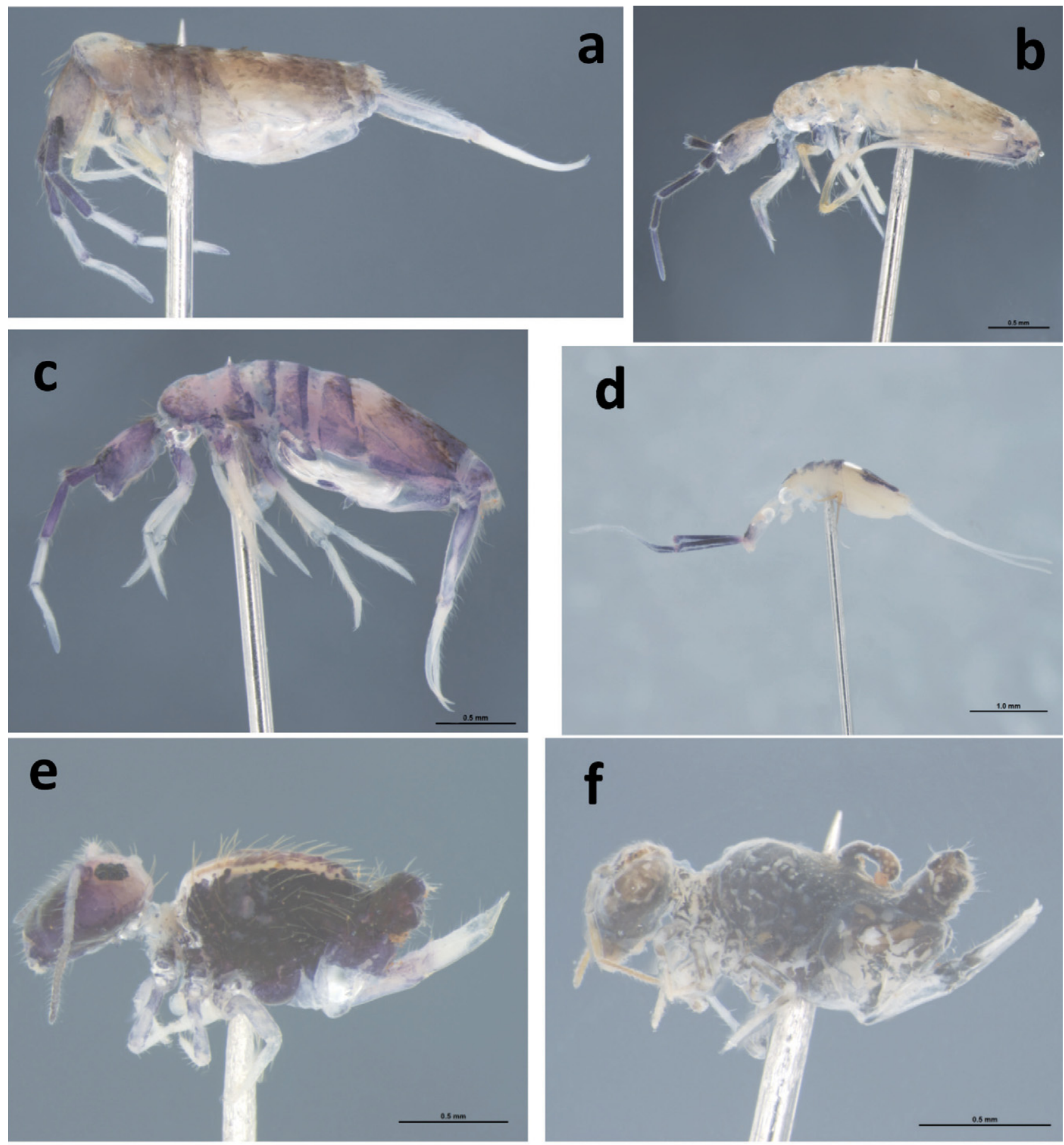

FIGURE 2

Colour photographs of Barrow Island Collembola taken from PaDIL (http://www.padil.gov.au/barrowisland/Search? sortType=ScientificName\&viewType=Details\&pageSize=10\&queryText1=Collembola\&q ueryType1=all). a) Acanthocyrtus sp., b) Calx sp., c) Acanthocyrtus barrowensis, d) Metacoelura sp.,

e) Rastriopes sp., f) Corynephoria sp.

very large extension range for the genus.

A new Acanthocyrtus species was found during surveillance in pitfalls set within the gas plant development area. It had not been collected during the baseline survey and was unusual for the genus in that it lacked all pigment but ocelli were present. Because of the total lack of pigmentation, it was likely that it normally lived in a subterranean habitat and had most probably been brought to the surface by the injection of water into the ground from air conditioner units set on buildings on the site. 


\section{DISCUSSION}

Eighteen species of the 71 species from the island are described or belong to a known species group but the level of island endemism seems low, as most species have been collected from other localities in northern Australia. However, it is possible that some of the undescribed species from soil and those from bore holes may be short-range endemics. Only one species, Acanthocyrtus barrowensis (Zhang et al. 2009) (Figure 2c), has been described from Barrow Island material. It is so far only known from the island but it most probably also occurs on the adjacent mainland, where the Collembola fauna is unknown apart from an earlier collection from the Hamersley Ranges. The same is true of the Calx species, which represents a new generic record for Australia.

As with other fauna and flora, Collembola assemblages are influenced and to some extent determined by climate, vegetation and soil characteristics, and historical aspects. Over the short term, the immediately previous and current weather influences what is collected on any single occasion.

The Barrow Island Collembola species list includes those that possess strategies to survive dry conditions as well as those that are only active during, or shortly following, moist conditions. In these respects the fauna of the island is typical of the fauna of arid Australia, particularly in the genera Acanthocyrtus, Drepanura, Drepanosira, Metacoelura, Corynephoria, Prorastriopes and Rastriopes (Figures 2a,c-f). Species in these genera were active even in dry conditions. Other species were only found after rain, such as those in the genera Sphaeridia, Pygicornides, Folsomides and Xenylla. Genera characteristic of the wet dry tropics and often found abundantly in this region are Stenognathellus and Temeritas. Some of these species are likely to have desiccation resistant eggs and in the case of Folsomides species, a cryptic anhydrobiotic stage as an adult also.

On the evidence so far, because of strict quarantine, it is unlikely that more NIS species will establish on the island. However, if they do, the surveillance sampling regime is unlikely to detect them as it is limited in site location and methods used. The species most likely to invade and colonise the island are those that live in the soil and in coastal, particularly, marine littoral or supra-littoral habitats. This is because the former can be carried in fairly small quantities of soil such as on boots or soil moving equipment (McNeill et al. 2011 and included references) while the latter can be carried on ships' hulls in encrusting plants and animals or floating marine debris. Some examples are Mesaphorura sp. and Onychiuridae in soil and Hypogastrura viatica Carl, in marine debris (Greenslade 2002).
The most vulnerable species to local extinction as a result of environmental change or habitat loss are likely to be those belong to genera considered rare, that is those that are present in low numbers and in few collections not only on Barrow Island but also in north western Australia. The Pygicornides species was only collected once, but in reasonable numbers, after a significant rainfall event. It is likely therefore to be secure as desiccation-resistant eggs are likely to persist in various locations on the island over long periods. Alternatively, the Calx species, also only collected once but not in atypical weather conditions, are likely to be very limited in distribution, and hence vulnerable to extinction if the location is disturbed in any way. Also, two of the marine littoral species, cf. Kenyura sp. and Caufrenyllodes sp., both representing new species not known from Australia and from only a single beach, could be vulnerable to disturbance from human impacts to beaches. Finally, another group of vulnerable species are the subterranean fauna, with several possible local endemic species. One cave suffered inappropriate dumping of rubbish in the past, but current threats could be from seepage into subterranean cavities of any type of pollutant in draining water from the gas plant, air strip or accommodation. It is recommended that monitoring of all waste water from the camp and gas plant location for pollutants be continued. While only a few beaches were sampled during this survey, the marine littoral species of Kenyura and Caufrenyllodes appear to be restricted in distribution and occur on beaches with particular characteristics; it is recommended that no vehicle and foot traffic be permitted at their localities. It is well documented that even light traffic can completely eliminate populations of interstitial fauna (Schlacher et al. 2007). In addition, the site on which the Calx species was recorded may require protection given the current known local distribution of this taxon. This genus is of particular importance as it has not yet been recorded from mainland Australia.

\section{ACKNOWLEDGEMENTS}

Thanks are due to members of the Barrow Island project team at Curtin University for collecting and separating Collembola samples for dispatch to me for identification. The Western Australian Museum lent a collection of subterranean Collembola.

\section{REFERENCES}

Callan, S. K., Majer, J. D., Edwards, K. and Moro, D. (2011). Documenting the terrestrial invertebrate fauna of Barrow Island, Western Australia. Australian Journal of Entomology 50: 323-343.

Department of Environment and Conservation (DEC), (2011). Barrow group nature reserves draft 
management plan. Department of Environment and Conservation: Perth.

Greenslade, P. (2002). Assessing the risk of exotic Collembola invading subantarctic islands: prioritising quarantine management. Pedobiologia 46: 338-344.

Greenslade, P. (2003). Collembola of Lord Howe Island. Unpublished Report to the Australian Museum: Sydney.

Greenslade, P. (2005). Collembola (springtails) of Sweers' Island and Pennefather River with notes on some other invertebrates. (pp. 227-238). In: Gulf of Carpentaria Scientific Study Report. Geography Monograph Series 10. The Royal Geographical Society of Queensland Inc.: Brisbane.

Greenslade, P. (2006). The Invertebrates of Macquarie Island. Australian Antarctic Division: Kingston.

Greenslade, P. (2009). Soil invertebrate diversity of different landscape units at Cravens Peak with a focus on Collembola (pp. 151-198). In: Cravens Peak Scientific Study Report. Geography Monograph Series. The Royal Geographical Society of Queensland Inc.: Brisbane.

Greenslade, P. (2010). Report of survey of Collembola on Barrow Island, June $6^{\text {th }}$ to $10^{\text {th }}$ 2010. Report to Chevron Australia Pty Ltd.: Perth.

Greenslade, P. and Kitching, R. (2011). Potential effects of climate warming on the distribution of Collembola along an altitudinal transect in Lamington National Park, Queensland, Australia. Memoirs of the Queensland Museum Nature 55: 333-347.

Greenslade, P., Florentine, S. and Horrocks, G. (2012). Invertebrates and extreme events: responses of ants and springtails to a flood and fire in arid Australia. Soil Organisms. 84: 569-587.

Humphreys, G., Alexander, J., Harvey, M. S. and Humphreys, W. F. (2013). The subterranean fauna of
Barrow Island, north-western Australia: 10 years on. Records of the Western Australian Museum, Supplement 83: $145-158$.

Larsen, T. (2007). Unravelling collembolan life below ground: stoichiometry, metabolism and release of carbon and nitrogen. Ph D. Thesis, University of Aarhus: Denmark.

Majer, J. D, Callan, S., Edwards, K., Gunawardene, N. and Taylor, C. (2013). Baseline survey of the terrestrial invertebrate fauna. Records of the Western Australian Museum, Supplement 83: 13-112.

McNeill, M., Phillips, C., Young, S., Shah, F., Aalders, L., Bell, N., Gerard, E. and Littlejohn R. (2011). Transportation of nonindigenous species via soil on international aircraft passengers; footwear. Biological Invasions 13: 2799-2815.

Moro D. and Lagdon, R. (2013). History and environment of Barrow Island. Records of the Western Australian Museum, Supplement 83: 1-7.

Schlacher, T. A., Dugan, J., Schoeman, D. S., Lastra, M., Jones, A., Scapini, F., McLachlan, A. and Defeo, O. (2007). Sandy beaches at the brink. Diversity and Distributions 13: 556-560.

Whittle, P., Jarrad, F. and Mengersen, K. (2013). Design of the Quarantine Surveillance for Non-Indigenous Species of Invertebrates on Barrow Island. Records of the Western Australian Museum, Supplement 83: 113-130.

Zhang F., Deharveng, L , Greenslade, Penelope and Chen, Jian-Xiu. (2009). Revision of the genus Acanthocyrtus (Collembola: Entomobryidae) and a description of a new genus from Eastern Asia. Zoological Journal of the Linnaean Society 157: 495-514.

MANUSCRIPT RECEIVED 22 NOVEMBER 2012; ACCEPTED 30 APRIL 2013. 